\title{
Effect of blood parasites on biomarkers of oxidative status in pigeons
}

\begin{abstract}
Parasites can effect on the health and productivity of birds. Haemoproteus columbae is a blood parasite that occurs in the members of Columbidae family especially pigeons. It can have serious effects on the health status of patients. One of the important effects of this parasite is on the reactive free radicals dynamic equilibrium in the body. In this investigation effect of Haemoproteus columbae as a blood parasite on the biomarkers of antioxidant system of pigeons was studied. According to our knowledge it is the first study on effect of blood parasites on biomarkers of oxidative status of pigeons. Totally 100 pigeons were studied in Shahrekord, locating in southwest of Iran. Blood samples were collected, blood smears prepared, stained and observed for presence of Haemoproteus columbae. Then biomarkers of antioxidant system were measured via via laboratory methods in plasma extracted from infected and healthy pigeon's samples as a control. Results show that blood lipid peroxidation (TBARS), Ferric Reducing Ability of Plasma (FRAP), uric acids concentration and catalases activity increased significantly $(\mathrm{P}<0.05)$ in infected pigeons versus healthy pigeons but superoxide dismutase activity decreased in infected pigeons. In conclusion results show that blood parasites can affect on oxidative state of patients, more detectable for FRAP and uric acids concentration of plasma. Totally it is clear that blood parasites make a change in dynamic equilibrium of reactive free radicals production and elimination.
\end{abstract}

Keywords: Antioxidant system, Blood parasite, Oxidative stress, Pigeons
Research Article

Volume 7 Issue I - 2018

\author{
Amir Dehghani Samani,' Khodadad Pirali \\ Kheirabadi, ${ }^{2}$ Abdonnaser Mohebbi,' Samin \\ Madreseh Ghahfarokhi, ${ }^{3}$ Azam Dehghani \\ Samani ${ }^{4}$ \\ 'Department of Clinical Sciences, Faculty of Veterinary Medicine, \\ Shahrekord University, Iran \\ ${ }^{2}$ Department of Pathobiology, Faculty of Veterinary Medicine, \\ Iran \\ ${ }^{3}$ Department of Clinical Sciences, Faculty of Veterinary Medicine, \\ Ferdowsi University of Mashhad, Iran \\ ${ }^{4}$ Faculty of Veterinary Medicine, Shahrekord University, Iran
}

Correspondence: Amir Dehghani Samani, Department of Clinical Sciences, Faculty of Veterinary Medicine, Shahrekord University, Shahrekord, II 5, Iran, Tel +98-38I 4424427, Fax 983814424427, Email amirds2008@gmail.com

Received: February 0I, 2018| Published: February 23, 2018

\section{Introduction}

During the health state and normal conditions, the production of reactive free radicals and their elimination is in a dynamic equilibrium that is known as oxidative status. This balance can be changed when the generation of free radicals becomes higher than the protection capacity of systemic antioxidant defense or reversely when the capacity of antioxidant system to protection against free radicals become lower than production of reactive free radicals. The impaired equilibrium between production of reactive free radicals and their elimination in humans or animals bodies known as oxidative stress and it can happen during the pathogenesis of numerous diseases, including parasitic infections. ${ }^{1,2}$ Usually, Haemoproteus species are known as avian haemosporidian parasites because most of them are avian specific parasites. ${ }^{3}$ Haemoproteus columbae occurs in Columbidae family member especially in pigeons worldwide and most times in tropical and subtropical regions. ${ }^{4}$ The natural hosts of this parasite include domestic pigeons (Columba Iivia domestica), many species of wild pigeons, mourning doves (Zenaidura macroura), turtle doves and other wild bird species. The gamonts of Haemoproteus columbae develop from tiny forms to elongated, crescent-shaped forms, which partially encircle the nucleus of the host cell. The host cell's nucleus may be displaced but not to the edge of cell. The mature gamonts of Haemoproteus columbae occupy the host cell completely. They distort it and push the host cell's nucleus to one side. ${ }^{5}$ From the ancient times till now pigeons and doves can fond easily in urban, suburban, rural and every areas of world. Their interaction with humans and other domestic and wild animals, make them as a potential carrier of different organisms like zoonotic micro-organisms. Also because of their great populations, parasitic infection can be common in their flocks. Parasites can effect on bird health directly via feeding from their bodies and causing irritation, discomfort, tissue damage, blood loss, allergies and dermatitis or indirectly via influence on metabolisms or other biological dynamic equilibrium in their bodies that cause disease and reduction of quality and quantity of meat and egg production in commercial flocks. Parasites can be regarded as the basic causes of stress, retardation in growth, lowered vitality and poor conditions of the birds. ${ }^{6}$ Parasites can affect on production of reactive free radicals and their elimination is in a dynamic equilibrium. In this among blood parasites have hidden effect on the host health; they are inside the host's blood or even inside the blood cells so their influence can be hidden even till death of hosts. ${ }^{1,2}$ According to our knowledge and till this date, there is not any research about the effects of blood parasites on dynamic equilibrium between production and elimination of reactive free radicals or oxidative status in birds. So in this study we concentrated on effects of blood parasites (Haemoproteus columbae) on the biomarkers of oxidative status of pigeons via measuring of blood lipid peroxidation products (malondialdehyde, MDA), the Ferric Reducing Ability of Plasma (FRAP) as a Measure of "Antioxidant Power" of plasma, Uric acids concentration in plasma and the activities of superoxide dismutase (SOD) and catalase (CAT), as primary enzymes in the antioxidant system.

\section{Materials and methods}

\section{Birds for experiment}

Totally 100 pigeons collected from different part of Shahrekord city (latitude, $32^{\circ} 19^{\prime} 32^{\prime \prime} \mathrm{N}$ and longitude, $50^{\circ} 51^{\prime} 52^{\prime \prime} \mathrm{E}$ ), located in southwest of Iran were studied in this experiment. In the first step, pigeons were screened for the presences of Haemoproteus columbea 
via laboratory method describe in the next paragraph. 24 pigeons were identified as infected by Haemoproteus columbea according to the identifying keys for gamonts inside the erythrocytes. ${ }^{5}$ They were separated from other pigeons then both groups were kept for 30 day in separated metal cages. During these times, environmental condition was same for both groups with the average temperature of $25^{\circ} \mathrm{C}$, humidity of $45-50 \%$ approximately, natural light time of about 14 hours daily, with free access to water and diet without any limits during 24 hours daily. Diet and water was same for both groups, diet was the common diet for pigeons contained 2 part wheat, 1 part millet and 1 part safflower. During the experimental period, birds were monitored carefully for presence of any abnormal signs and diseases. After 30 days blood samples were taken from 24 infected pigeons and also 24 healthy pigeons (chosen randomly from 76 healthy pigeons) as control group. Blood smears of both groups were prepared, stained and observed for the presence of blood parasites.

\section{Blood sampling}

Before the sampling, bleeding site was cleaned via scrubbing cotton with ethanol $70 \%$. After the evaporation of ethanol from site, blood samples were collected via puncturing from brachial vein, using 22 gauge disposable sterile needles and syringes. About 2-4 $\mathrm{ml}$ blood were collected from each pigeon. Bloods were immediately transferred into labeled tubes. For each sample half of taken blood was transferred to tube without any anticoagulant agent and other half was transferred to tube containing ethylene di amine tetra acetic acid (EDTA) at $3 \mathrm{mg}$ for each $\mathrm{ml}$ blood as anticoagulant.

\section{Preparing the blood smears}

Small amounts of blood $(\sim 50 \mu 1)$ were used for preparing the smears. Smears were dried by heating and then were fixed in absolute methanol for 2-5 minutes and finally were stained with giemsa staining $10 \%$ for $15 \mathrm{~min}^{3,4}$

\section{Diagnose of Haemoproteus columbae infection in blood smears}

Stained blood smears were observed for presence of Haemoproteus columbae gamonts inside the erythrocytes via optic microscope lens $40 \times$ and 100×. Gamonts of Haemoproteus columbae developed from tiny forms to elongated, crescent-shaped forms, which partially encircled the nucleus of the erythrocytes. Diagnoses of infected pigeons were confirmed in department of parasitology, faculty of veterinary medicine, Shahrekord University, Shahrekord, Iran. ${ }^{3,5}$

\section{Preparing the plasma and serum for biochemical studies}

Plasma extraction from tubes with anticoagulant agent were immediately done and tubes without anticoagulant agent were kept in $37^{\circ} \mathrm{C}$ for 30 minutes without any movement in order to blood coagulation, then their serums were extracted. Tubes containing collected bloods with/without anticoagulant agent were centrifuged at 2000 - $3000 \mathrm{rpm}$ for $15 \mathrm{~min}$ and plasmas/serums were separated for the biochemical studies. Remaining plasmas/serums were immediately frozen at $-70^{\circ} \mathrm{C}$.

\section{Measurement of the Ferric Reducing Ability of Plasma (FRAP)}

The Ferric Reducing Ability of Plasma (FRAP) as a measure of "Antioxidant Power" of plasma was measured by Automated
FRAP assay. This test was performed on a Cobas Fara centrifugal analyzer (Roche) following the manufacturer's instructions and using commercially available calibrators and quality control samples. A Cobas Fara centrifugal analyzer was used to perform the FRAP assay as follows: $300 \mu \mathrm{l}$ freshly prepared FRAP reagent was warmed to $37^{\circ} \mathrm{C}$ and a reagent blank reading was taken (M1) at $593 \mathrm{~nm} ; 10$ $\mu \mathrm{l}$ of sample was then added, along with $30 \mu \mathrm{H} 2 \mathrm{O}$; final dilution of sample in reaction mixture was, therefore, 1/34. Absorbance $(A)$ readings were taken after $0.5 \mathrm{~s}$ and every $15 \mathrm{~s}$ thereafter during the monitoring period. The change in absorbance $\left(\Delta A_{593 \mathrm{~nm}}\right)$ between the final reading selected and the M1 reading was calculated for each sample and related to $\triangle A 593_{\mathrm{nm}}$ of a $\mathrm{Fe}^{\mathrm{II}}$ standard solution tested in parallel. In this study the reaction was monitored for up to $30 \mathrm{~min}$, but the 4-min readings were selected for calculation of FRAP values. Finally the FRAP as a measure of "Antioxidant Power" of plasma was expressed as $\mu \mathrm{mol} \mathrm{Fe} / \mathrm{ml}^{7}$

\section{Measurement of the uric acids concentration}

Uric acids concentration was measured by Uric Acid Assay Kitab65344 (Abcam, England). All the steps were according to the manufacturer's instructions. $50 \mu \mathrm{L}$ of standard solution for standard and $50 \mu \mathrm{L}$ of serums for each samples were transferred to plate's holes, $50 \mu \mathrm{L}$ Reaction Mix were added to each holes. Then plates were incubated at $37^{\circ} \mathrm{C}$ for 30 minutes, protected from light. At the end step, colorimetric assay was done via ELISA (Enzyme-Linked Immunosorbent Assay) reader and measuring at OD570 $\mathrm{nm}$ and finally uric acids concentration was expressed as $\mathrm{mg} / \mathrm{dl}$.

\section{Measurement of blood lipid peroxidation (TBARS)}

Lipid peroxidation was measured using the Thiobarbituric acid reactive substances (TBARS) assay according to the method described by Buege and Aust. ${ }^{8}$ Malonaldehyde (MDA) was dissolved in tetramethoxy propane, which decomposes under assay conditions to give MDA and is used as the standard in the range of 0.0-7.50 nmol of MDA in $500 \mu \mathrm{L}$. One milliliter of TBARS working solution was added to samples or standard tubes, then heated for 20 minutes at $100^{\circ} \mathrm{C}$, and centrifuged at $1000 \mathrm{rpm}$ for 10 minutes. The absorbance of the supernatant was read spectrophotometrically at $532 \mathrm{~nm}$ against the blank. The data are expressed as $\mu \mathrm{mol} / 1 .^{8,9}$

\section{Measurement of superoxide dismutase (SOD) activity}

Plasma SOD activity was estimated using the Nitro Blue Tetrazolium (NBT) dye reduction test (SOD Test Wako, Wako Pure Chemical Industries, and Osaka, Japan). A serum sample $(0.1 \mathrm{ml})$ was added to the reaction mixture $(2 \mathrm{ml})$, which contained $0.20 \mathrm{mM}$ xanthine, $0.12 \mathrm{mM}$ Nitro Blue Tetrazolium, 0.049IU xanthine oxidase, and $0.1 \mathrm{M}$ phosphate buffer $(\mathrm{pH} 8.0)$. The mixture was incubated for $20 \mathrm{~min}$ at $37^{\circ} \mathrm{C}$. In the reaction mixture, the superoxide radical produced reduces NBT to NBTH2. The rate of reduction of NBT was measured at $560 \mathrm{~nm}$. The results for SOD activity were expressed as the percent inhibition of these reactions by SOD. ${ }^{10}$

\section{Measurement of catalase (CAT) activity}

Two hundred $\mu \mathrm{l}$ of serum was incubated in $1.0 \mathrm{ml}$ substrate ( $65 \mu \mathrm{mol} / \mathrm{ml}$ hydrogen peroxide in $60 \mathrm{mmol} / \mathrm{l}$ sodium-potassium phosphate buffer, $\mathrm{pH} \mathrm{7.4)}$ at $37^{\circ} \mathrm{C}$ for $60 \mathrm{~s}$. Serum catalase activity is linear up to $100 \mathrm{kU} / 1$. If the catalase activity exceeded $100 \mathrm{kU} / \mathrm{l}$, the serum was diluted with the phosphate buffer (2- to lo-fold) and the assay was repeated. One unit catalase decomposes $1 \mu \mathrm{mol}$ of hydrogen peroxide/l min under these conditions. The enzymatic reaction was 
stopped with $1.0 \mathrm{ml}$ of $32.4 \mathrm{mmol} / 1$ ammonium molybdate $\left(\left(\mathrm{NH}_{4}\right)_{6}\right.$ $\left.\mathrm{Mo}_{7} \mathrm{O}_{24} 4 \mathrm{H}_{2} \mathrm{O}\right)$ and the yellow complex of molybdate and hydrogen peroxide was read spectrophotometrically at $405 \mathrm{~nm}$ against the blank. The serum catalase activity expressed as kU/1. ${ }^{11}$

\section{Statistical analysis}

The data were expressed as the Mean \pm Standard Error of the Mean (SEM) using Sigma plot (version 12) software. Tukey test was used for post hoc analysis. A value of $(\mathrm{P} \leq 0.05)$ was considered significant.

\section{Results}

\section{Ferric Reducing Ability of Plasma (FRAP)}

Result of this study shows that FRAP as a measure of antioxidant power of plasma not only increased in infected pigeons significantly $(\mathrm{P}<0.05)$ versus healthy pigeons, but also this increase was more sensible than other biomarkers. Ferric Reducing Ability of Plasma in control group was $798.191 \pm 61.618 \mu \mathrm{mol} \mathrm{Fe} / \mathrm{ml}$ but in infected pigeons, a great and significant increase was observed and FRAP in them was $1020.261 \pm 81.123 \mu \mathrm{mol} \mathrm{Fe} / \mathrm{ml}$ (Figure 1).

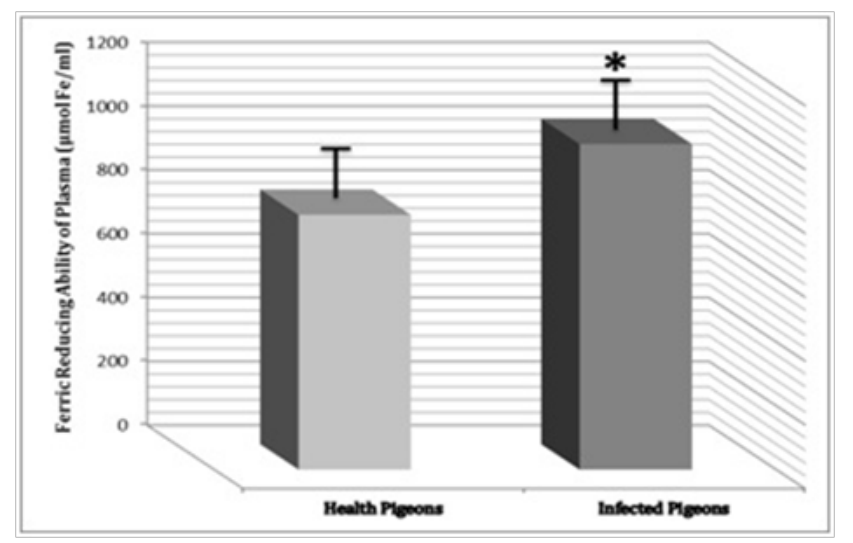

Figure I Ferric Reducing Ability of Plasma (FRAP) had increase in infeted pigeons versus healthy pigeons. Presence of *shows the significant $(P<0.05)$ differences between groups.

\section{Uric acids concentration}

Result of this investigation clears that there was a significant increase $(\mathrm{P}<0.05)$ in the uric acids concentration in infected pigeons versus healthy pigeons. Uric acid concentration in control group was $6.358 \pm 0.485 \mathrm{mg} / \mathrm{dl}$ but in infected pigeons, it was $9.892 \pm 0.746 \mathrm{mg} /$ dl (Figure 2).

\section{Blood lipid peroxidation products (TBARS)}

Malonaldehyde (MDA) concentration increases significantly $(\mathrm{P}<0.05)$ in infected pigeons versus healthy pigeons. Malonaldehyde concentration in control group was $3.513 \pm 0.285 \mu \mathrm{mol} / \mathrm{l}$, but it was $4.316 \pm 0.388 \mu \mathrm{mol} / \mathrm{l}$ in infected pigeons (Figure 3).

\section{Superoxide dismutase (SOD) activity}

Results of this study shows SOD activity decreased in infected pigeons versus healthy pigeons but this decrease was not significant $(\mathrm{P}<0.05)$. SOD activity in control group was $13.041 \pm 0.672 \%$, but it was $12.612 \pm 1.025 \%$ in infected pigeons (Figure 4).

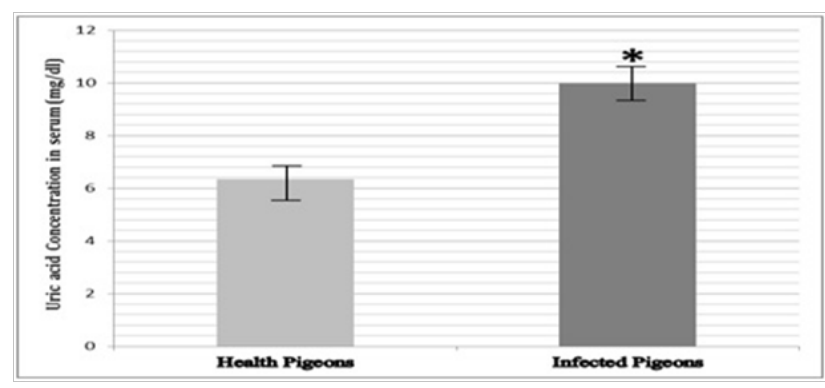

Figure 2 Uric acid concentration in infected pigeons had increase versus healthy pigeons. Presence of $*$ shows the significant $(\mathrm{P}<0.05)$ differences between groups.

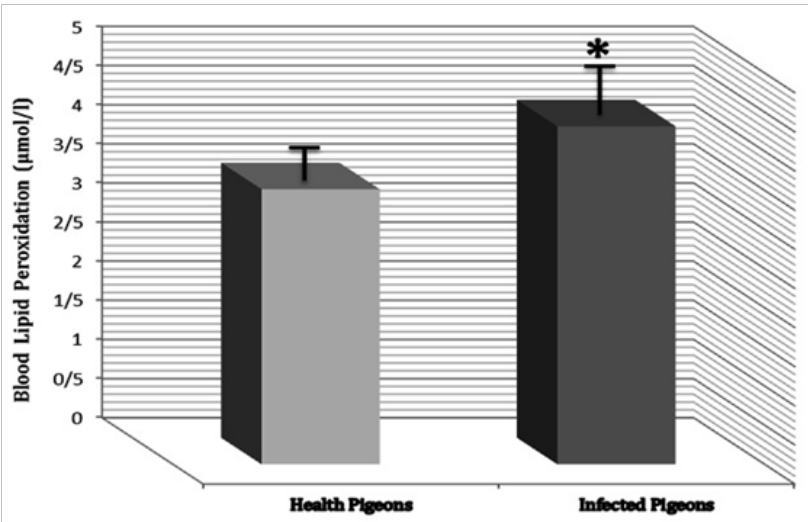

Figure 3 MDA concentration (Blood lipid peroxidation) in infected pigeons had increase versus healthy pigeons. Presence of $*$ shows the significant $(\mathrm{P}<0.05)$ differences between groups.

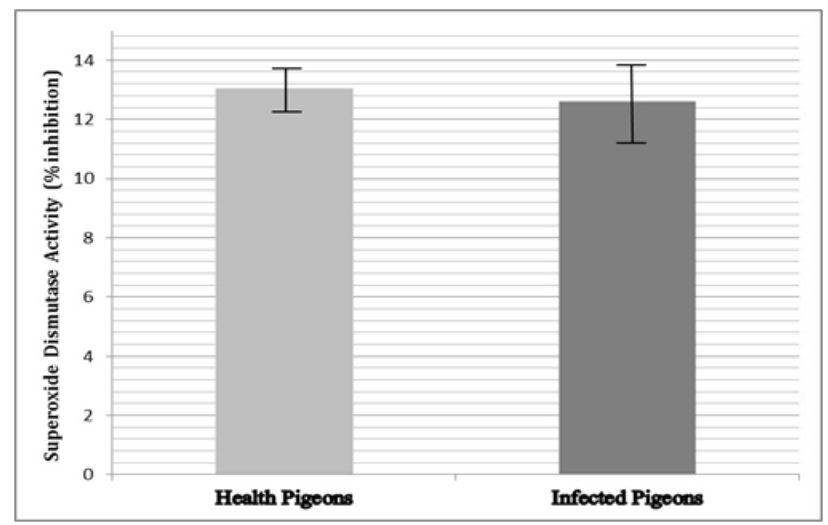

Figure 4 SOD activity in infected pigeons had decrease versus healthy pigeons but this decrease was not significant.

\section{Catalase (CAT) activity}

There was a significant $(\mathrm{P}<0.05)$ increase in the CAT activity in infected pigeons versus healthy pigeons. CAT activity in control group was $17.728 \pm 1.174 \mathrm{kU} / 1$, but in infected pigeons, CAT activity was $19.842 \pm 0.871 \mathrm{kU} / 1$ (Figure 5). 


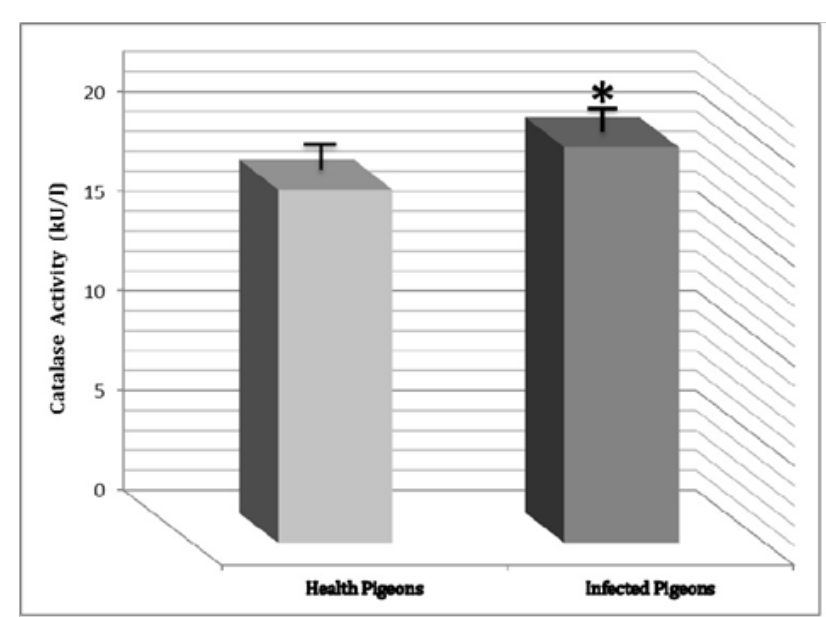

Figure 5 CAT activity in infected pigeons had increase versus healthy pigeons. Presence of shows the significant $(P<0.05)$ differences between groups.

\section{Discussion}

Results of this study show that parasitic infection can influence dynamic equilibrium between production and elimination of reactive free radicals in body. This equilibrium is known as oxidative status. Many studies reported that blood parameters most commonly associated with health of individuals and also serological and hematological values can be an important source of information and can provide or support an objective assessment of the health status. ${ }^{12-14}$ In this study the effect of blood parasites on blood parameters of oxidative status as an important system in human and animals bodies were studied, focusing on biomarkers of antioxidant systems in pigeons. Bibliographic reports demonstrate that oxidative stress occurs during the pathogenesis of parasitic diseases. ${ }^{9,15}$ But according to our knowledge and this time there are no reports about effect of blood parasites in birds and this is the first work in this way. Results of current study agree with results of other studies that reported presence of oxidative stress during the pathogenesis of parasitic diseases. This study shows that blood lipid peroxidation (TBARS), Ferric Reducing Ability of Plasma (FRAP), uric acids concentration and catalases activity increased significantly $(\mathrm{P}<0.05)$ in infected pigeons versus healthy pigeons but superoxide dismutase activity decreased in infected pigeons. These results confirm that dynamic equilibrium between production and elimination of reactive free radicals changes during the pathogenesis of blood parasite infections. The oxidative stress is manifested primarily via alterations of antioxidant enzyme activities and the reductions of some non-enzymatic antioxidants such as the vitamins $\mathrm{A}, \mathrm{C}$ and $\mathrm{E} .{ }^{15}$

The superoxide dismutase is involved in the antioxidant defense system in a first attempt to control and eliminate the toxic reactive oxygen species (ROS). ${ }^{16,17}$ Result of this study shows that superoxide dismutase activity decreased in infected pigeons. Maybe this decrease occurs because of failure in producing of enough antioxidant enzymes against oxidative stress conditions related to parasitic infection. But in every condition this decrease shows that during the pathogenesis of parasitic diseases, potency of body against reactive free radicals reduces and then oxidative stress will occur due to weakness of antioxidant system. According to Amstad et al. ${ }^{18}$ the decrease of the activities of antioxidant enzymes could have a negative impact on cellular resistance against the oxidant induced damage of cell genome and cell killing. ${ }^{18}$

Other hypothesis is extra production of reactive free radicals like reactive oxygen species (ROS) in the bird's bodies (even in healthy condition) that it can be amplified during the infection due to presence of many stress conditions with together. There are many reasons why production of ROS is higher in the body of birds, for example: avian breeding cycle and production of egg can produce extra toxic metabolites like ROS. ${ }^{19}$ In these category energetic demands and resource constraints are assumed to be greater. ${ }^{19}$ In the body of birds, fly and heightened physical activity need more energy and will make their bodies more metabolically active. ${ }^{20,21}$ But extra amount of ROS only are seen in infected birds. In these birds, ROS may be elevated for additional reasons. Firstly, immune activation may have been triggered by the parasitic infection. Oxidant-producing cellular immune responses are known to be involved in the control of parasitic infection. ${ }^{22}$ Secondly, in infected birds; ROS are also produced as a direct result of the metabolism of the parasite itself. During its life stages within the hosts' red blood cells, the parasite degrades hemoglobin and uses the amino acids gained for its own growth. ${ }^{23}$ The degradation products like haeme monomers are capable to generate toxic oxidants. ${ }^{24}$ The occurrence of direct oxidative effect has been confirmed for Haemoproteus. ${ }^{23}$ So it will be clear that parasitic infection can make changes in biomarkers of oxidative status. In current study blood parasite's infection make the great changes in FRAP Uric acid concentration in plasma, Blood lipid peroxidation products, SOD activity and CAT activity in infected birds than healthy birds. There are several reports evidencing the presence of antioxidant disequilibrium in birds with parasitic diseases, it was observed in chickens with eimeriosis, hypovitaminosis $\mathrm{C} .{ }^{25}$ According to other investigators, the blood levels of vitamin A and xanthophylls concentrations in chickens, infected with E. acervulina, were very low. ${ }^{26}$ Gabrashanska et al. ${ }^{27}$ reported a deficiency of antioxidant vitamins $\mathrm{C}$ and $\mathrm{E}$ in chickens infected with Ascaridia galli. ${ }^{27}$ The equilibrium between the activity and the intracellular amounts of antioxidant enzymes is vital for the survival and the health of aerobic organisms. These decreases in antioxidant vitamins in infected birds make significant effects on oxidative status of infected birds. In other hand every factors that make significant changes in antioxidant material in cells can affect on biomarkers of oxidative status in infected birds. ${ }^{28}$ Result of current study is in agree with these studies and confirms them. Antioxidant enzyme catalase (CAT) is important for adaptation of cells to oxidative stress and preserved cells via degradation of the reactive hydrogen peroxide..$^{29}$ In current study there is a significant increase in CAT activity in infected birds versus healthy birds. This increase is a subsequent answer of cells against increasing production of oxidant metabolites in cells in result of parasitic infection. In infected bird reactive oxygen species (ROS) will produce more than normal condition so subsequent answer of cells against this increase in ROS is increasing of production of CAT to eliminate extra reactive metabolites. Nagler et al..$^{30}$ observed that vitamin A and $\beta$-carotene increased systemic antioxidant properties and decreased lipid peroxidation. In other hand presence of antioxidant material (same as antioxidant vitamins in cells) have significant decreasing effects on 
production of lipid peroxidation products..$^{30}$ In current study parasitic infection made a significant increase in oxidative stress conditions then increasing of lipid peroxidation products (that are oxidative products in cells) occurred due to this oxidative stress condition respectively.

\section{Conclusion}

In conclusion this study shows the significant $(\mathrm{P}<0.05)$ increase in blood lipid peroxidation products (TBARS), Ferric Reducing Ability of Plasma (FRAP), uric acids concentration and catalase activity and also a decrease in superoxide dismutase activity. This study confirms that oxidative status is influenced by parasitic infection. Next studies can focus on intra cellular events due to blood parasite's infection

\section{Acknowledgments}

The authors are grateful to Deputy of Research, University of Shahrekord for financial support of this project and all of persons whom helped them to do this research.

\section{Conflict of interest}

Authors certify that there are no any financial and personal relationships with other people or organizations that could influence or bias their work and authors declare that there is no conflict of interest.

\section{References}

1. Dallaul R, Lileehoj H, Shelem D, et al. Effect of vitamin A deficiency on host intestinal immune response to E. acervulina in broiler chickens. Poult Sci. 2002;81(10):1509-1515.

2. Gawain MW, Baker DH. Eimeria acervulina infection in the chicken: A model system for estimating nutrient requirements during coccidiosis. Poult Sci. 1981;60(8):1884-1891.

3. Samani AD, Kheirabadi KP, Mohebbi A. Effect of Haemoproteu columbae infection on the hemogram of the Pigeons (Columba livia domestica). J Parasitic Dis. 2016;40(4):1406-1410.

4. Gupta DK, Jahan N, Gupta N. New record of haemoproteous and plasmodium (Sporozoa: Haemosporida) of rock pigeons (Columba livia) in India. J Parasitic Dis. 2011;35(2):155-168.

5. Charles Hendrix. Diagnostic Parasitology for Veterinary Technicians.4th Edition. Amsterdam: Elsevier; 2011. p. 175-176.

6. Ruff MD. Important parasites in poultry production systems. Vet Parasitol. 1999;84(3):337-347.

7. Benzie IF, Strain JJ. The ferric reducing ability of plasma (FRAP) as a measure of antioxidant power: the FRAP assay. Anal Biochem. 1996;239(1):70-76.

8. Buege JA, Aust SD. Microsomal lipid peroxidation. Methods in enzymology. 1978;52:302-310.

9. Dede S, Deger Y, Deger S, et al. Determination of the status of lipid peroxidation and antioxidants in sheep infected with certain endoparasites (Fasciola sp., Trichostongilidae sp., Eimeria spp.). Acta Parasit Turc. 2000;24:190-193.

10. Yasuda M, Takesue F, Inutsuka S, et al. Prognostic significance of serum superoxide dismutase activity in patients with gastric cancer. Gastric Cancer. 2002;5(3):148-153.

11. Goth LA. Simple method for determination of serum catalase activity and revision of reference range. Clinica Chimica Acta. 1991;196(2):143151.
12. Toro $\mathrm{H}$, Saucedo $\mathrm{C}$, Borie $\mathrm{C}$, et al. Health status of free living pigeon in the city of Santiago. Avian Pathol. 1999;28:619-623.

13. Schulz JH, Bermudez AJ, Tomlinson JL, et al. Blood plasma chemistries from wild mourning doves held in captivity. $J$ Wild life Dis. 2000;36(3):541-545.

14. Norte AC, Sheldon B, Sousa JP, et al. Repeatability and method dependent variation of blood parameters in wild caught Great Tits Palus major. Acta Ornithol. 2008;43(1):66-75.

15. Dede S, Deger Y, Kahraman T, et al. Oxidation products of nitric oxide and the concentration of antioxidant vitamins in parasitise goats. Acta Vet Brno. 2002;71:341-345.

16. Evans P, Halliwet B. Micronutrients: oxidant/antioxidant status. J Nutr. 2001;85(2):S67-74.

17. Mc Cord JM. The superoxide free radical. Its biochemistry and pathophysiology. Surgery. 1983;94(3):412-414.

18. Amstad P, Moret R, Cerutti P. Glutathione peroxidase compensates for the hypersensitivity of $\mathrm{Cu}, \mathrm{Zn}$-superoxide dismutase overproducers to oxidant stress. J Biol Chem. 1994;269(3):1606-1609.

19. Daan S, Masman D, Groenewold A. Avian basal metabolic rates: their association with body composition and energy expenditure in nature. $\mathrm{Am}$ J Physiol Reg. 1990;259:333-340.

20. Loft S, Astrup A, Buemann B.et al. Oxidative DNA damage correlates with oxygen consumption in humans. The FASEB Journal. 1994;8(8):534537.

21. Costantini D, Cardinale M, Carere C. Oxidative damage and anti-oxidant capacity in two migratory bird species at a stop-over site. Comp Biochem Phys. 2007;144(4):363-371.

22. Ots I, Horak P. Health impact of blood parasites in breeding great tits. Oecologia. 1998;116(4):441-448.

23. Chen MM, Shi L, Sullivan DJ. Haemoproteus and synthesize heme polymers similar to Plasmodium hemozoin and beta-hematin. Mol Biochem Parasitol. 2001;113(1):1-8.

24. Sullivan DJ. Theories on malarial pigment formation and quinoline action. Intl J Parasitol. 2002;32(13):1645-1653.

25. Challey J. The effect of caecal coccidiosis infections and experimental hemorrhage upon adrenal ascorbic acid levels in the chickens. $J$ Parasitol. 1960;46(6):727-731.

26. Ruff MD, Fuller HL. Some mechanism of reduction of carotenoid levels in chickens infected with E. acervulina or E. tenella. J Nutrition. 1975:105:1447-1456.

27. Gabrashanska M, Morros MG, Tsocheva-Gaytandzieva N, et al. Antioxidant status in Ascaridia galli infected chicks treated with zinccopper double basic salts. Athens: Proc 4th Int Sym on Trace Elements; 2003.

28. Davydova MN, Sabirova RZ. Antioxidative Enzymes of SulfateReducing Bacterium (Desulfovibrio desulfuricans): Superoxide Dismutase and Peroxidases. Biochemist. 2002;67(7): 822-825.

29. Popova M, Popov CH. Effect of heavy metal salts on the activity of rat liver and kidney catalase and lysosomal hydrolases. $J$ Vet Med A. 1998;45(6):343-351

30. Nagler LG, Lankin VZ, Kozachenko AI, et al. Rate of Free-Radical Oxidation of C18 Diene and Triene. Fatty Acids in Aqueous Micellar Solutions and Effectiveness of fl-Carotene as an Inhibitor of their Oxidation. Biochemist. 2003;68(2):203-209. 